\title{
Research on the Development of Hospice Care in Beijing
}

\author{
Shuli Gao, Yiping Liu, Yuxin Cai, Jixin Jiao, Jianqing Bi \\ Business College, Beijing Union University, Beijing, China \\ Email: shuli.gao@buu.edu.cn
}

How to cite this paper: Gao, S.L., Liu, Y.P., Cai, Y.X., Jiao, J.X. and Bi, J.Q. (2021) Research on the Development of Hospice Care in Beijing. Journal of Biosciences and Medicines, 9, 33-41.

https://doi.org/10.4236/jbm.2021.92004

Received: January 4, 2021

Accepted: February 19, 2021

Published: February 22, 2021

Copyright $\odot 2021$ by author(s) and Scientific Research Publishing Inc. This work is licensed under the Creative Commons Attribution International License (CC BY 4.0).

http://creativecommons.org/licenses/by/4.0/

(c) (i) Open Access

\begin{abstract}
In recent years, hospice care in Beijing has developed rapidly. In order to further promote the development of hospice care in Beijing, this paper first analyzes the current situation of hospice care in Beijing, and then analyzes the existing problems of hospice care in Beijing, such as insufficient funds, lack of medical staff, no unified public information platform and low acceptance of hospice care. In view of the existing problems, the paper puts forward relevant policy suggestions for the development of hospice care in Beijing, such as increasing financial support, strengthening the propaganda and education of hospice care, strengthening the training of professional talents, improving the voluntary service system, formulating reasonable access standards, and building a unified public information platform, so as to further promote the effective, healthy and rapid development of hospice care in Beijing development.
\end{abstract}

\section{Keywords}

Beijing, Hospice Care, Current Status

\section{Introduction}

According to the National Bureau of Statistics, by the end of 2019 in China, the population aged over 60 years has reached 254 million people, which is $18.1 \%$ of the total population, and the elderly population aged over 65 years has reached 176 million people, which is $12.6 \%$ of the total population ${ }^{1}$. The China Development Report 2020: development trends and policies on aging of the Chinese population, issued by the China development foundation, predicts that China will enter an aged society from the aging society around 2022, and this rate is much faster than that of other major developed countries. Our country not only 'http://www.stats.gov.cn/tjsj/zxfb/202001/t20200119_1723767.html. 
has a severe aging problem, but also has a persistently high incidence and mortality rate of cancer [1]. In late 2020, the international agency for research on cancer (IARC), under the World Health Organization (WHO), released a report on the most recent estimates of the global status of the burden of cancer. The report states: with the aging and rapid growth of the population, the number of cancer incidence and death worldwide is also in a rapidly growing situation ${ }^{2}$. China, as a country with a very large population, accounts for much of the cancer incidence and death in Asia. In the context of a rapidly growing elderly population, increasing average life expectancy, and a continuing rise in malignant conditions such as cancer, the need for hospice care has become more prominent, and its services have become more problematic [2]. Hospice care means the provision of care and humane care for patients at the end stage of the disease or for elderly patients before dying, through the control of symptoms of pain and discomfort, physical, psychological, spiritual, and other aspects, in order to improve the quality of life, and help patients to be comfortable, safe, and dignity to leave [3] [4]. Hospice care is not only aimed at patient's unwell symptoms for analgesia and sedation, comfort care, but also to develop psychological and humane care for patients and their families [5]. The development of hospice care embodies the progress of social civilization, and it has now become one of the important livelihood issues. The hospice care in Beijing has been developed relatively rapidly in recent years, and this article is based on the current status and existing issues in the development of Beijing hospice care, making recommendations for the development, so as to promote effectively, healthily, and considerably.

\section{Current Situation of Hospice Care in Beijing}

In 1987, Songtang hospice care Hospital was officially established. It is the first hospice care institution in Beijing. It mainly provides hospice care services for endangered patients. After that, hospice care institutions in Beijing gradually developed, but there was no policy, measure and system guarantee for hospice care before 1994. After that, with the introduction of a series of policies to encourage institutions to carry out hospice care services, hospice care in Beijing has developed to a certain extent, but it is still relatively slow. In 2016, after the government made it clear to strengthen the construction of hospice care and other continuing medical institutions, Beijing received greater support. In March 2017, 15 medical institutions including Beijing Longfu hospital were selected by Beijing Municipal Health and Family Planning Commission as the first batch of Beijing hospice care pilot institutions ${ }^{3}$. Desheng community health service center is the only hospice care ward in the city. In October of the same year, Haidian District of Beijing became the first batch of five pilot cities of hospice care in China, which explored hospice care actively. Chu Ju's house, the first hospice ward for children in Beijing, was also set up in 2017. In May 2019, the ${ }^{2}$ https://www.iarc.who.int/faq/latest-global-cancer-data-2020-qa/. ${ }^{3}$ http://www.xinhuanet.com//local/2017-05/08/c_1120933040.htm. 
National Health Commission launched the second batch of hospice care pilot projects. Xicheng District of Beijing became one of the pilot projects of hospice care. By the end of 2019, there are 24 hospice Care institutions in Beijing, and 647 beds can be provided, of which 19 have been included in the designated medical insurance 4 . In December 2020, Peking Union Medical College Hospital and Beijing hospital will be designated as "Beijing palliative guidance center"; nine hospitals, including Shougang Hospital of Peking University, Beijing Tsinghua Changgeng Hospital Affiliated to Tsinghua University, Beijing Geriatric Hospital, Beijing Haidian Hospital, Beijing Wangfu integrative Hospital of Chinese and Western medicine, and Beijing Shunyi traditional Chinese medicine hospital, will be designated as "the first batch of hospice care base demonstration centers in Beijing"5.

\section{Problems of Hospice Care in Beijing}

At present, the capacity of hospice care services in Beijing is gradually enhanced. There are various forms such as independent hospice care centers. At the same time, hospice care wards and beds are set up in general hospitals, specialized hospitals, nursing homes, community health service centers, etc. to increase service resources, gradually extend to basic medical institutions, communities and homes, and increase the number of hospice care beds to a certain extent [6]. It can meet the hospice Care needs of people. Although hospice care in Beijing has entered an all-round development stage and made some achievements, there are still some problems as follows:

First of all, hospice care in Beijing is facing the problems of insufficient funds and unequal distribution of resources, which are also common problems in hospice care in China. According to the report of Beijing Aging Office, in 2019, the resident population of Beijing aged 60 and above will reach 3.713 million, accounting for $17.24 \%{ }^{6}$, which shows a more prominent aging problem. At the same time, with the high incidence of malignant diseases and other problems, the demand for hospice care in Beijing is increasing. As a social public welfare, the income of hospice care is far lower than that of private institution or enterprise. For some institutions, the whole day medical expenses of dying patients are obviously not enough to support the normal operation of hospice care institutions. There is still a big shortage in the financial support of hospice care project [7]. At present, there are many hospice care institutions in Beijing, but the resource allocation of hospice care is uneven. For example, the beds of tertiary general hospitals are very tight, so it is often difficult to increase the related supporting resources. The internal medicine ward of oncology will treat some patients with advanced cancer who have no conditions for treatment and receive terminal patients, so the resources are also relatively tight. At present, there is no ${ }^{4}$ http://www.bjnews.com.cn/news/2019/12/25/666067.html. ${ }^{5}$ http://wjw.beijing.gov.cn/zwgk_20040/ylws/202012/t20201224_2184464.html. ${ }^{6}$ https://bjrbdzb.bjd.com.cn/bjrb/mobile/2020/20201019/20201019_005/content_20201019_005_1.ht $\underline{\mathrm{m}}$. 
unified standard for admission of hospice care. Some pension institutions are also participating in the care of the seriously ill elderly. On the one hand, these institutions are basically based on life care, and it is difficult to guarantee the palliative treatment, psychological intervention and comprehensive care for dying patients. On the other hand, pension institutions are often unable to define whether some patients belong to hospice care or disease care.

Secondly, there is a lack of medical staff and professional quality. Hospice care is not equal to medical work. A reasonable hospice care team should be composed of doctors, nurses, social workers, nutritionists, psychologists and other personnel [8]. At present, in Beijing, there are few employees engaged in hospice care, and the medical staff are generally lack of hospice care education and clinical practice. Most of the training for hospice care is only focused on medical staff, while the training for social workers is less [9]. Medical staff play a variety of roles, not only to reduce the suffering of patients as a doctor, but also as psychological guidance in the face of death, and providing life care and medical care of patients. At present, there is a relative lack of volunteers in hospice care, although there are many active palliative volunteer teams in Beijing, such as the palliative volunteer team of Peking Union Medical College/Peking Union Medical College, hospice care center of Peking University Shougang Hospital, hospice care project team of Cihui public welfare foundation, and so on. These palliative volunteer teams are insufficiently trained since they generally faced with the problem of insufficient operating funds [10].

Third, there is no unified public information platform for hospice care. Although there are more hospice care institutions in Beijing than in other cities, the family members of patients have less information of hospice care related institutions, wards. In particular, the charging standards of hospice care institutions are not clarified, and lack of valuable information. Although there is a lot of related information on the internet, it is difficult for patients' families to find exact what they need.

Fourth, due to the influence of traditional concepts, people's acceptance of hospice care needs to be improved. Under the influence of Confucianism, traditional concept of death and traditional filial piety, for their parents, children prefer that as long as there is a glimmer of hope, they should do their filial piety, especially with the relatively high level of medical treatment in Beijing [7]. However, for some end-stage patients, active treatment has long been meaningless. On the one hand, patients are suffering from meaningless treatment, on the other hand, it increases the economic burden, and causes the waste of social medical resources, too.

\section{Policy Suggestions on Hospice Care in Beijing}

In view of the problems in the development of hospice care in Beijing, we can promote the development of hospice care by increasing financial support, strengthening professional personnel training, publicity and education, and building a comprehensive medical security system. 


\subsection{Increase Financial Support}

The development of hospice care is closely related to the income level of residents in social economy, security system and medical level of hospitals. At present, the hospice care resources in Beijing are relatively scarce, which cannot meet the medical service needs of patients. Although 19 hospice care institutions in Beijing have been included in the medical insurance by the end of $2019^{7}$, for more patients, the resources of these medical institutions are relatively limited. If they cannot carry out hospice care in these medical institutions, the economic burden of patients will be heavy. Therefore, hospice care can be considered to be included in the scope of medical insurance to reduce people's medical burden, so as to reduce the economic pressure of patients and have the willingness to try hospice care [11] [12]. The government should increase financial support for hospice care, support to construct relevant institutions and departments, and encourage all districts to actively implement relevant public health policies and constantly innovate the linkage system of medical care and nursing. For example, Chaoyang District formulated "Guidelines for the construction of hospice care department in Community Health Service Center (Trial)" in 2019, through which the grassroots policy security system of hospice care can be constructed ${ }^{8}$. In addition to the government's financial support, we can also consider issuing welfare lottery to raise funds, take various ways to encourage social forces and charitable organizations to provide hospice care services, and provide some preferential and support in tax and management, so as to escort the development of hospice care services.

\subsection{Strengthen the Propaganda and Education of Hospice Care}

Public education is very important for the development of hospice care. Death is an essential link in the law of life, but the public's awareness of death education is not enough. Under the influence of traditional culture, many people taboo talking about "death" related issues. In fact, birth, aging, illness and death are the natural process of life. It needs social guidance to make the public have a correct view of the end of life [13]. Nowadays, the rapid development of information technology benefits everyone. The government can strengthen the public's cognitive education of life through various channels, such as the Internet, various media, expert consultation, cultural lectures, hospital visits, community seminars and so on, so that people can learn to recognize death, respect death and accept death [14]. In October 2019, the guidance on the establishment and improvement of the elderly health service system jointly issued by the National Health Commission proposed to "strengthen the publicity and education of the public, and promote the concept of hospice care to be widely recognized and accepted by the society". We can take a variety of publicity methods to increase the publicity and popularization of hospice care knowledge, so that more people can understand hospice care and accept it better in consciousness. Some good prac-

${ }^{7}$ http://epaper.ynet.com/html/2019-12/26/content_345491.htm?div=-1.

${ }^{8}$ http://www.bjchy.gov.cn/dynamic/news/8a24fe836d5afd5f016d5d51c553082c.html. 
tices should be vigorously promoted and used for reference. For example, the Beijing Association for the promotion of pre-natal orders has carried out the "quiet tree planting" pre-natal orders promotion project by placing exhibition shelves of promotion materials in public areas such as hospitals, schools and apartments for the elderly, and by free reading, so as to benefit the elderly in nursing homes, hospital inpatients and other key potential groups. In addition, we can publicize and explain to young people, guide them to respect life and cherish the present, and have a more accurate understanding of hospice care. Through inheritance, we can make change to the social status quo and develop hospice care.

\subsection{Strengthen the Training of Professional Talents}

Hospice care needs multidisciplinary team cooperation. We need not only hospice doctors and nurses, but also pain management specialists, psychiatrists, pharmacists, nutritionists, rehabilitation physiotherapists, volunteers and social workers who have received corresponding training [15]. The construction of talent team plays an important role in improving the quality of hospice care service. Therefore, in the aspect of personnel training, systematic design is needed. First of all, we should establish the corresponding education and qualification certification system, and increase the strength of personnel training. Hospice care is faced with special patient groups, special management methods and special needs, so it is necessary to establish a training system for corresponding groups [16]. In the second half of 2020, Beijing has carried out two phases of training for the key medical staff of hospice care to help the hospice care service develop scientifically and standardized. The follow-up training for hospice care personnel should not only continue to strengthen the systematic training for medical staff, but also provide relevant training for social workers and volunteers. Secondly, we should establish a multi-disciplinary cooperation system and strengthen the construction of multi-disciplinary team talents. Hospice care needs compound knowledge in many fields. We can strengthen the cooperation of related subjects by establishing a reasonable incentive mechanism. Third, improve the salary of hospice care personnel, so as to retain talents, stabilize the team, and ensure the orderly and efficient operation of the work. Since hospice care needs no expensive examination or expensive drugs, and a lot of communication, humanistic care is not included in the charge. Domestic hospice wards are in a state of loss, and the salary of medical staff is also at a relatively low level [17]. Therefore, the relevant management system should be established to ensure the salary of hospice care personnel.

\subsection{Improve the Voluntary Service System}

At present, the development of hospice care in China is still in its infancy. In the relevant hospice care practice guidelines, it was proposed that "give full play to the role of volunteers or social support system in the follow-up and support of 
bereavement". Volunteers are an important part of social forces in hospice care, and their participation will play a positive role in promoting the development of hospice care [18]. We can play the role of government guidance actively, build a professional volunteer training platform for hospice care, and establish a perfect volunteer training system to provide more comprehensive services for patients in need. In particular, many colleges and universities gather in Beijing to actively carry out lectures on hospice care. Through the wide awareness of relevant knowledge, it can not only increase college students' understanding of hospice care project, but also improve the level of college students' volunteer participation in hospice care service. Due to the particularity of hospice care volunteer service, it requires volunteers to have strong psychological quality, endurance ability, good communicating skills and empathy ability, which need a certain period of professional training, continuous guidance [19]. In the construction of volunteer service system, we can adopt the hierarchical and diversified service mode according to the different professional background and ability of volunteers, and form the healthy competition among volunteers by establishing the corresponding assessment mechanism.

\subsection{Formulate Reasonable Access Standards and Build a Unified Public Information Platform}

By the end of 2019, there have been 24 hospice care institutions in Beijing, which can provide 647 hospice care beds. It is estimated that by 2022, Beijing will achieve the goal of 1000 hospice care beds ${ }^{9}$. At present, the resources of hospice care in Beijing are very limited, so it is necessary to establish reasonable access standards. In this way, doctors can make clear what kind of patients are treated, and patients can also know under what circumstances they need to choose hospice care [20]. At present, patients and their families lack a comprehensive and in-depth understanding of the information about hospice care [21], such as the servicing place, the specific modes, charges, number of beds and other information. Therefore, a unified public information platform should be constructed to collect the information of hospice care providers, so as to reduce the information asymmetry of patients and their families.

China is entering a period of accelerated development of aging population, and the demand for hospice care services is also increasing. Hospice care is a systematic project, which needs not only the support of the government and the guarantee of the system and funds, but also the professional and high-quality nursing staff, supplemented by voluntary service. Hope that through multi-agent cooperation, more and more hospice patients can complete their lives with dignity.

\section{Acknowledgements}

This paper was supported by "Venus" College Students' Scientific and Technological Innovation and Entrepreneurship Project of Beijing Union University in ${ }^{9}$ https://news.bjd.com.cn/2020/12/28/38954t100.html. 


\section{Conflicts of Interest}

The authors declare no conflicts of interest regarding the publication of this paper.

\section{References}

[1] Yang, F.J., Che, H., Wang, H.Y. and Wang, L. (2019) Study on Main Problems and Solutions of Hospice Care in China. Chinese Medical Ethics, 12, 1562-1565.

[2] Zhu, L.Y., Li, C.Y. and Zhou, X.L. (2020) Research Progress of Hospice Care for the Elderly in China Chinese Journal of Gerontology, 12, 2684-2687.

[3] Li, Y.G., Luo, Z.W., Qin, Y. and Zhang, Z.T. (2019) Problems and Countermeasures of Hospice Care in China. Soft Science of Health, 7, 28-32.

[4] Wu, X.L. (2020) Research Progress of Hospice Care Development and Service Mode in China. Chinese General Practice Nursing, 7, 2661-2664.

[5] Chen, Y.Y., Wu, X.J., Li, X.Y., Cheng, Q.Q. and Mao, T. (2019) Development of Hospice Care Under the Background of Healthy China Construction. Chinese Nursing Management, 6, 801-805.

[6] Schubaue, M., Zhang, L.X., Wu, X.M., Ning, X.H. and Lu, Y.H. (2016) Reflections on Palliative Care in Beijing. Journal of Cancer Education, 8, 1-3.

[7] Gong, Y.N., Li, F.R., Ni, K.W., et al. (2018) Operational Status of Hospice Care Wards in Beijing. Chinese Journal of General Practice, 26, 3223-3226.

[8] Xie, Q. (2019) Die Safely: Construction and Improvement of Hospice Care Service System. Chinese Public Administration, 12, 28-32.

[9] Liang, L.J. and Zhang, G.G. (2018) Research on Chinese Mainland Hospice Care. Practical Geriatrics, 1, 20-22.

[10] Zhang, M.Y. and Ning, X.H. (2020) Research on the Development of Palliative Volunteer Team in Beijing. Medicine \& Philosophy, 11, 25-29+79.

[11] Xie, Q. (2019) Death with Dignity: The Establishment and Improvement of the Service System in Hospice Palliative. Care Chinese Public Administration, 12, 28-32.

[12] Wang, M.M., Xu, T.M. and Yue, P. (2020) The Relevant Policies, Challenges and Suggestions of Hospice Care in China. Medicine \& Philosophy, 7, 19-22.

[13] Chen, L.F., Deng, W.Y., Xu, M.L. and Zhang, L. (2020) Practice of Multidisciplinary Cooperative Hospice Care for Cancer Dying Patients in Tertiary General Hospital. Journal of Nursing, 15, 56-59.

[14] Ye, M.J., Liu, X.B., Zheng, L.Q., Wu, T.T. and Liu, E. (2020) Role of Professional Nursing Team in Hospice Care in Geriatric Ward. Journal of Traditional Chinese Medicine Management, 28, 92-94.

[15] Du, X.R., Fan, Y.X., Chen, J.Y. and Zhang, Y.X. (2020) Practice of Humanistic Care in Hospice Care. General Nursing, 20, 2519-2522.

[16] Ning, X.H. (2019) Mainland China Should Vigorously Develop Hospice and Hospice Care: Experience of Peking Union Medical College Hospital. Chinese Medical Ethics, 3, 293-298.

[17] Jiang, S., Ma, L. and Li, Z. (2019) Medical Care and Spiritual Care in Palliative Practice. Chinese Medical Ethics, 3, 299-302.

[18] Mi, Y.X., Yang, X.W., Ren, Y.T., et al. (2019) Present Situation of College Students 
in Beijing Participate in Hospice Care Volunteer Service: An Interview Study. Medicine and Philosophy, 19, 28-31.

[19] Zhang, A.J., Wang, Z.G., Wang, X.J., Fan, J., Zhao, B.Y. and Mao, C.M. (2019) Practice of "Medical Social Worker + Volunteer" in Accompany Service of Hospice Patients. Social Work in China, 12, 45-48.

[20] Miu, J., Zhang, R.Y., Cao, W.Q. and Shen, T.H. (2019) Study on Admittance and Exit Criteria of Hospice Care in Community. Chinese Journal of General Practice, 12, 2063-2068.

[21] Zeng, J., Jin, L., Sun, Y. Pan, L., Li, Y.F. and Shi, B.X. (2019) A Qualitative Study on the Cognition of Medical Staff on the Admission Standard of Hospice Care. Chinese General Practice, 21, 2602-2605. 